\title{
RESEARCH
}

Open Access

\section{USF1 deficiency alleviates inflammation, enhances cholesterol efflux and prevents cholesterol accumulation in macrophages}

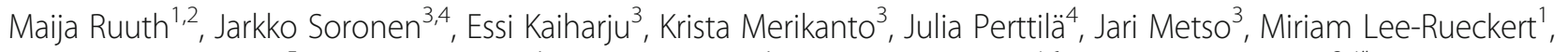
Marja-Riitta Taskinen ${ }^{5}$, Petri T. Kovanen ${ }^{1}$, Katariina Öörni', Vesa M. Olkkonen ${ }^{4,6}$, Matti S. Jauhiainen ${ }^{3,4^{*}}$ (1) and Pirkka-Pekka Laurila $3,7,8$

\begin{abstract}
Background: The focus of studies on high-density lipoproteins (HDL) has shifted from HDL-cholesterol (HDL-C) to $\mathrm{HDL}$ function. We recently demonstrated that low USF1 expression in mice and humans associates with high plasma $\mathrm{HDL}-\mathrm{C}$ and low triglyceride levels, as well as protection against obesity, insulin resistance, and atherosclerosis. Here, we studied the impact of USF1 deficiency on HDL functional capacity and macrophage atherogenic functions, including inflammation, cholesterol efflux, and cholesterol accumulation.

Methods: We used a congenic Usf1 deficient mice in C57BI/6JRccHsd background and blood samples were collected to isolate HDL for structural and functional studies. Lentiviral preparations containing the USF1 silencing shRNA expression vector were used to silence USF1 in human THP-1 and Huh-7 cells. Cholesterol efflux from acetylLDL loaded THP-1 macrophages was measured using HDL and plasma as acceptors. Gene expression analysis from USF1 silenced peritoneal macrophages was carried out using Affymetrix protocols.

Results: We show that Usf1 deficiency not only increases HDL-C levels in vivo, consistent with elevated ABCA1 protein expression in hepatic cell lines, but also improves the functional capacity of HDL particles. HDL particles derived from Usf1 deficient mice remove cholesterol more efficiently from macrophages, attributed to their higher contents of phospholipids. Furthermore, silencing of USF1 in macrophages enhanced the cholesterol efflux capacity of these cells. These findings are consistent with reduced inflammatory burden of USF1 deficient macrophages, manifested by reduced secretion of pro-inflammatory cytokines MCP-1 and IL-1 $\beta$ and protection against inflammation-induced macrophage cholesterol accumulation in a cell-autonomous manner.

Conclusions: Our findings identify USF1 as a novel factor regulating HDL functionality, showing that USF1 inactivation boosts cholesterol efflux, reduces macrophage inflammation and attenuates macrophage cholesterol accumulation, linking improved macrophage cholesterol metabolism and inflammatory pathways to the antiatherogenic function of USF1 deficiency.
\end{abstract}

Keywords: USF1, High density lipoproteins, Cholesterol efflux, Cholesterol accumulation, Macrophage, Hepatocyte, Inflammation

\footnotetext{
* Correspondence: matti.jauhiainen@thl.fi

${ }^{3}$ Genomics and Biomarkers Unit, National Institute for Health and Welfare,

Fl-00251 Helsinki, Finland

${ }^{4}$ Minerva Foundation Institute for Medical Research, Tukholmankatu 8, 00290

Helsinki, Finland

Full list of author information is available at the end of the article
}

(c) The Author(s). 2018 Open Access This article is distributed under the terms of the Creative Commons Attribution 4.0 International License (http://creativecommons.org/licenses/by/4.0/), which permits unrestricted use, distribution, and reproduction in any medium, provided you give appropriate credit to the original author(s) and the source, provide a link to the Creative Commons license, and indicate if changes were made. The Creative Commons Public Domain Dedication waiver (http://creativecommons.org/publicdomain/zero/1.0/) applies to the data made available in this article, unless otherwise stated. 


\section{Introduction}

Low level of high-density lipoprotein cholesterol (HDL-C) is a major independent risk factor for atherosclerotic cardiovascular disease [1]. However, recent studies have shown that raising HDL-cholesterol (HDL-C) levels by pharmacological agents does not translate into better clinical outcomes. The HDL-C raising agent niacin and CETP inhibitors, when administered on top of statins, both failed to reduce cardiovascular events despite markedly increasing HDL-C levels [2-4]. Furthermore, Mendelian randomization studies using complex genetics have shown that variants associated exclusively with high HDL-cholesterol levels, are not associated with reduction in cardiovascular outcomes [5]. These findings suggest that HDL-C is unlikely to be causally related to cardiovascular disease. Thus, research efforts have shifted from HDL-C levels to HDL function.

The canonical functions of HDL particles include their anti-inflammatory and antioxidative properties, as well as their role in the initiation of reverse cholesterol transport [6]. Cholesterol efflux from cells to circulation is the first and rate-limiting step in reverse cholesterol transport. Recently, strategies to measure cholesterol efflux capacity of apolipoprotein B-depleted plasma have been successfully used in clinical studies, revealing inverse correlations between cholesterol efflux capacity and prevalent coronary artery disease, even stronger than HDL-C levels [7, 8]. Indeed, the levels of circulating HDL-C do not strictly reflect the cholesterol molecules released from the macrophage foam cells typical of atherosclerotic lesions, neither do they exert any of the anti-atherogenic activities of HDL [9]. Thus, further understanding of the factors affecting cholesterol efflux might reveal a higher atheroprotective potential than HDL-C targeting agents.

The upstream stimulatory factor 1 (USF1) was originally associated with familial combined hyperlipidemia [10] with subsequent associations with lipid levels [11] $[12,13]$, coronary atherosclerosis [14], and acute cardiovascular events [15]. We recently showed that inactivation of USF1 in mice protects against atherosclerosis, insulin resistance, obesity, and hepatic steatosis [16]. The beneficial metabolic phenotype of this mouse model was linked to increased whole-body energy expenditure and brown adipose tissue activity. Furthermore, Usf 1 deficiency corrected diet-induced dyslipidemia in mice, manifested by reduced triglycerides and elevated levels of HDL-C. The atheroprotective role of USF1 deficiency was also observed in humans, in whom individuals having a USF1 mRNA expression reducing allele displayed elevated HDL-C and reduced triglyceride levels, as well as reduced atherosclerosis in coronary arteries, also featuring fewer calcified plaques [16]. However, whether the elevated HDL-C was associated with an improved functionality of HDL particles was not addressed in the previous study. We now investigate whether USF1 affects pathways involved in macrophage cholesterol accumulation, with particular focus on cholesterol efflux, the rate-limiting step in reverse cholesterol transport, and whether the elevated HDL-C of Usf1 deficient animals translates into improved HDL function.

\section{Materials and methods In vivo experiments \\ Animals}

We use a congenic strain in $\mathrm{C} 57 \mathrm{Bl} / 6)$ RccHsd background in our studies with littermate controls. All animal procedures were reviewed and approved by the local animal care committee and local government authorities. The generation of Usf1 deficient mice has been previously described [16].

\section{Isolation and composition of mouse HDL}

HDL was isolated from pooled mice serum samples by sequential ultracentrifugation using Table-Top ultracentrifuge (Beckmann Optima TL, USA) and $\mathrm{KBr}$ for density adjustment. Serum samples were first adjusted to the density (d) of $1.019 \mathrm{~g} / \mathrm{mL}$ and the centrifuge tube filled with a $\mathrm{d}=1.019 \mathrm{~g} / \mathrm{mL} \mathrm{KBr}$ solution to the total volume of $3 \mathrm{~mL}$. The samples were centrifuged at $+5^{\circ} \mathrm{C}$ for $2 \mathrm{~h}$ at relative centrifugal field 500,000 x G. After centrifugation very low and intermediate density lipoproteins (VLDL and IDL) were recovered in the top $1 \mathrm{~mL}$ fraction and the bottom was adjusted to the density of $1.063 \mathrm{~g} / \mathrm{mL}$ using solid $\mathrm{KBr}$, filled to $3 \mathrm{~mL}$ with $\mathrm{d}=1.063$ $\mathrm{g} / \mathrm{mL} \mathrm{KBr}$ solution and centrifuged $\left(+5^{\circ} \mathrm{C}, 3 \mathrm{~h}, 500,000\right.$ $\mathrm{x} \mathrm{G}$ ). The top $1 \mathrm{~mL}$ fraction contained low density lipoproteins (LDL). To get the total mouse HDL fraction the LDL infranatant fraction was adjusted with solid $\mathrm{KBr}$ to the density of $1.21 \mathrm{~g} / \mathrm{mL}$, the vials filled with $\mathrm{KBr} 1.21 \mathrm{~g} /$ $\mathrm{mL}$ density solution and then centrifuged $\left(+5^{\circ} \mathrm{C}, 18 \mathrm{~h}\right.$, $500,000 \times$ G). Total HDL was obtained in top $1 \mathrm{~mL}$ fraction. The isolated HDL was dialyzed against phosphate-buffered saline (PBS, $\mathrm{pH}$ 7.4) and stored at $+4{ }^{\circ} \mathrm{C}$ before analysis. Isolated HDL was analyzed for lipids and APOA1 using the methods described below.

\section{Analysis of lipid and apoA-I concentration}

Isolated HDL particles were analyzed for total cholesterol (CHOD-PAP 1489232 kit; Roche Diagnostics $\mathrm{GmbH}$ ), choline-containing phospholipids (990-54,009; Wako Chemicals $\mathrm{GmbH}$ ) and triglycerides (GPO-PAP 1488872 kit; Roche Diagnostics $\mathrm{GmbH}$ ) using fully enzymatic methods. Mouse apolipoprotein A-I (apoA-I) was quantified by a sandwich enzyme-linked immunosorbent assay (ELISA) as described [17]. 


\section{Gene expression analysis from USF1 silenced peritoneal macrophages}

RNA was extracted using the RNeasy Mini Kit (Qiagen) according to manufacturer's instructions. Quality of RNA was analyzed using the Bioanalyzer platform (Agilent Technologies). Two micrograms of total RNA were treated according to standard Affymetrix eukaryotic RNA labeling protocols (Affymetrix, Santa Clara, CA). Fifteen micrograms of biotin labeled cRNA was fragmented according to Affymetrix eukaryotic sample protocol. Hybridization, staining, and washing of the Affymetrix HG-U133_Plus_2 Arrays were performed using the Affymetrix Fluidics Station 450 and Hybridization Oven 640 under standard conditions. The raw data were processed using the GCRMA-normalization method [18].

\section{Cholesterol accumulation in mouse peritoneal macrophages} Mouse peritoneal macrophages were collected from 8 weeks old female mice. Mice were pretreated 4 days with $500 \mu \mathrm{L}$ thioglycollate (BD, BLL ${ }^{\mathrm{Tm}}$ Thioglycollate Medium Brewer Modified). Macrophages were collected in 1\% BSA in PBS and cultured in D-MEM (Sigma) supplemented with $20 \% \mathrm{FBS}$ and $1 \%$ penicillin/streptomycin. Cells were cultured for 4 days before experimentation to remove the thioglycollate induced inflammation. For cholesterol loading peritoneal macrophages were incubated with acetylated LDL for $16 \mathrm{~h}$. Some samples were pre-treated with $10 \mathrm{ng} / \mathrm{mL}$ of LPS (Salmonella Minnesota $R 595$ ) for $24 \mathrm{~h}$ before loading. Lipids were extracted from the cells with organic solvent using $\mathrm{n}$-Hexane and isopropanol, 3:2 $(\mathrm{v} / \mathrm{v})$. After evaporation of the organic solvent under nitrogen the residual lipids were dissolved in methanol. Total cholesterol was measured with commercial kit (CHOD-PAP \# 1489232, Roche Diagnostics GmbH, Mannheim, Germany). Remaining cells after lipid isolation were collected and total protein was measured for adjustment of the final results.

\section{In vitro experiments}

\section{Silencing of USF1 in vitro}

The most effective USF1 silencing shRNA was screened in immortalized human hepatocytes (IHH). IHH were grown in William's E medium (GIBCO-Life Technologies, Carlsbad, CA) containing $10 \%$ fetal bovine serum (FBS), $2 \mathrm{mM} \mathrm{L}$-glutamine, $100 \mathrm{U} / \mathrm{mL}$ penicillin, $100 \mu \mathrm{g} /$ $\mathrm{mL}$ streptomycin, $100 \mathrm{nM}(20 \mathrm{mU} / \mathrm{mL})$ insulin, and 50 $\mathrm{nM}$ dexamethasone (Sigma-Aldrich, St. Louis, MO) on CellBIND ${ }^{\circ}$ Surface cell culture plates (Corning, Corning, NY). The human monocytic cell line, THP-1 and human hepatocellular carcinoma cell line, $\mathrm{HuH}-7$ were cultured in RPMI (THP-1) or DMEM (HuH-7) medium supplemented with $10 \%$ fetal bovine serum and penicillin/ streptomycin and to THP-1 media 25 mM HEPES was added. For transduction, 20,000 THP-1 cells seeded on 24-well plates or $\sim 80 \%$ confluent $\mathrm{HuH}-7$ cells in 12 -well plates were treated for $24 \mathrm{~h}$ with SIGMA MISSION lentiviral preparations containing either the control shRNA expression vector (MISSION ${ }^{\circledR}$ pLKO.1-puro Non-Target shRNA) or the USF1 silencing shRNA expression vector (233475) at a MOI of $\sim 1$. Cells were selected with $6 \mu \mathrm{g} /$ $\mathrm{mL}$ of puromycin for 14 days and were then used for cholesterol efflux assays.

Cell lines were found to be free of Mycoplasma contamination.

\section{Cholesterol efflux from THP-1 macrophages}

THP-1 human monocytes (ATCC, Manassas, VA) were grown at $37^{\circ} \mathrm{C}$ in suspension culture in RPMI 1640 medium supplemented with 10\% FBS, $25 \mathrm{mM}$ HEPES, and $1 \%$ penicillin/streptomycin. Differentiation into macrophages was performed using $100 \mathrm{nM}$ phorbol myristate acetate (PMA, Sigma) for 3 days. After this the differentiated macrophages were washed twice with PBS and loaded by incubation in the presence of $\left[{ }^{3} \mathrm{H}\right]$ cholesteryl oleate-labeled acetyl-LDL ( $25 \mu \mathrm{g}$ of protein/well) in RPMI 1640 supplemented with $5 \%(\mathrm{v} / \mathrm{v})$ lipoprotein-deficient serum, $10 \mathrm{mM}$ HEPES, pH 7.4, and penicillin/streptomycin for $48 \mathrm{~h}$ and without PMA. The cholesterol-loaded macrophage cells were then washed with PBS, and $2 \%$ serum or HDL (as determined by $25 \mu \mathrm{g} / \mathrm{mL} \mathrm{HDL}$ protein) derived from either $U_{s f 1^{-/-}}$or $U_{s f 1^{+/+}}$mice were added as cholesterol acceptors. After $24 \mathrm{~h}$ incubation, the growth medium was collected, and radioactivity was determined by liquid scintillation counting. The cell layer was washed with PBS, followed by addition of $0.2 \mathrm{M} \mathrm{NaOH}$ to lyse the cells and further incubated for $24 \mathrm{~h}$ at $+4{ }^{\circ} \mathrm{C}$, after which the radioactivity was assessed. Wells incubated without added acceptors were used as controls. Cholesterol efflux is expressed as dpm in medium divided by the cell protein content (unit used for the efflux: $\mathrm{dpm} / \mu \mathrm{g}$ cell protein).

\section{Western blot analysis of ABCA1}

Cells were lysed on ice with buffer (10 mM HEPES, 150 $\mathrm{mM} \mathrm{NaCl}, 0,5 \mathrm{mM} \mathrm{MgCl}_{2}, 10 \%$ Glycerol, $0,5 \%$ Triton $\mathrm{X}-100,0,5 \%$ deoxycholate, $\mathrm{pH}$ 7.4) containing protease inhibitors. Protein concentrations were determined, and equal amount of proteins were loaded on $4-12 \%$ SDS-PAGE gel (Bio-RAD) in sample buffer containing $\beta$-mercaptoethanol without heating. After electrophoresis the separated proteins in gel were electro-transferred to nitrocellulose membrane. Membrane was blocked with $5 \%$ milk TBS-T for $1 \mathrm{~h}$ and after washing immunostaining was performed with primary antibody (ABCA1, Bio-RAD and $\beta$-actin, Abcam), washed and followed by incubation with Chemiluminence (Daco) and IRDye 680RD (LI-COR) secondary antibodies. Immunoreactive proteins were detected with Super Signal West Femto Maxium Sensitivity Substrate (ThermoFisher 
Scientific) using chemiluminesence and infrared imaging system (LI-COR). Result were calculated with Image Studio Lite program and the ABCA1 signal was adjusted to $\beta$-actin.

\section{Cholesterol esterification measurements}

USF-1-silenced and control THP-1 macrophages were incubated with or without acetylated LDL (acLDL, $50 \mu \mathrm{g} / \mathrm{ml}$ ) in serum-free media for $24 \mathrm{~h}$. Cells were washed 3 times with PBS and incubated with $\left[{ }^{3} \mathrm{H}\right]$-oleic acid-BSA complexes in the serum-free medium for $2 \mathrm{~h}$, washed 3 times with PBS, and lipids were extracted with hexane/isopropanol $(3: 2, v / v)$. Samples of the cell suspensions were taken for protein determination and from the extracted lipids $\left[{ }^{3} \mathrm{H}\right]$-oleate incorporation into cholesteryl esters was analyzed using thin layer chromatography (TLC). The extracted lipids were separated by TLC in n-heptane/isopropyl ether/glacial acetic acid/ methanol (60:40:4:2, vol/vol). Spots corresponding to cholesteryl esters (CE) were scraped, the radioactivity measured by scintillation counting and the CE counts per total cell protein calculated.

For measuring the distribution of $\left[{ }^{14} \mathrm{C}\right]$-cholesterol between unesterified cholesterol (C) and CE USF-1-silenced and control THP-1 macrophages were incubated with $\left[{ }^{14} \mathrm{C}\right]$-cholesterol $(1 \mu \mathrm{Ci} / \mathrm{ml})$ in serum-free media for $24 \mathrm{~h}$, washed with PBS and chased in serum-free medium for $18 \mathrm{~h}$. Lipids were extracted and separated by TLC in n-hexane/diethyl ether/glacial acetic acid/water (65:15:1:0.25, vol/vol). Spots corresponding to $C$ and CE were scraped, the radioactivity measured by scintillation counting, and the $\left[{ }^{14} \mathrm{C}\right]-\mathrm{CE} /$ total $\left[{ }^{14} \mathrm{C}\right]$-cholesterol and $\left[{ }^{14} \mathrm{C}\right]-\mathrm{CE} /$ total cell protein ratios were calculated.

\section{Results}

As previously shown, the $U_{s f 1^{-/}}$mice displayed elevated levels of plasma total cholesterol and phospholipids [16]. Using fast protein liquid chromatography, we established that cholesterol and phospholipid concentrations were elevated in the HDL fractions of $\mathrm{Usf1}^{-1-}$ mice as compared $U_{s f} 1^{+/+}$mice [16]. In the present study, we first investigated whether USF1 inactivation in human macrophages affects cholesterol efflux from macrophage foam cells. We silenced USF1 in THP-1 macrophages using shRNA, achieving $79 \%$ silencing, and observed significant increase in cholesterol efflux capacity from these cells (Fig. 1a). This could be mediated by ABCA1, whose mRNA expression was upregulated by about 3.2-fold in the THP-1 cells subjected to USF1 knock-down (Fig. 1b) whereas the expression of $A B C G 1$ was downregulated (52\%), and that of SCARB1 (commonly known as SR-BI) remained unaltered. In Western blot analyses, consistent with higher $A B C A 1$ transcript abundance, ABCA1 displayed a trend of increase in USF1 silenced THP-1 macrophages (Fig. 1c). Interestingly, we also detected a significant increase of ABCA1 protein in human hepatoma cells subjected to USF1 knock-down (HuH7; Fig. 1d). Since USF1 has previously been identified as a repressor of ABCA1 [19], our results suggest that USF1 inactivation could boost both cholesterol efflux capacity of macrophages as well as enhance nascent HDL particle secretion from the liver, contributing to the HDL elevation observed in $U_{s f 1^{-/-}}$mice [16].

In addition to studying the impact of USF1 on the key cholesterol transporters, we also studied its effects on cholesterol acceptors. Serum derived from $U s f 1^{-/-}$mice displayed enhanced capacity to induce cholesterol efflux from THP-1 foam cells as compared to $\mathrm{Usf1}^{+/+}$serum (Fig. 2a). Interestingly, when the experiment was repeated with HDL isolated from mouse sera, the acceptor capacity of $U s f 1^{-/-}$derived HDL was superior to that of $U s f 1^{+/+}$HDL (Fig. 2b), explaining the enhanced serum facilitated removal of cholesterol from macrophage foam cells. Thus, both enhanced cholesterol transporter expression and cholesterol acceptor functionality appear to boost the first step of macrophage-specific reverse cholesterol transport in conditions of USF1 deficiency.

Elevated levels of HDL-C are associated with improved HDL lipid composition in humans [20, 21], and increased HDL phospholipid content has been reported to confer better cholesterol acceptor properties to HDL particles [22, 23]. We next studied whether HDL composition accounts for the higher cholesterol efflux efficiency resulting from USF1 inactivation. The HDL particles derived from $\mathrm{Usfl}^{-/-}$mice were enriched in phospholipids and cholesterol while the proportional amount of apolipoprotein A1 (APOA1) was decreased (Fig. 2c), indicating a higher phospholipid/APOA1 mass ratio in HDL. The higher proportion of phospholipids (PL) provides a plausible explanation to the elevated cholesterol acceptor capacity of $U_{s f 1^{-/-}}$derived HDL particles. Importantly, the concentrations of phospholipids, cholesterol, and APOA1 were elevated in the HDL fraction derived from $U s f 1^{-/}$mice (Fig. 2d). Together, these findings explain the functional superiority of $U s f 1^{-/-} \mathrm{HDL}$ and serum as acceptors in cholesterol efflux.

Because increased uptake of modified LDL by macrophages promotes the generation of cholesterol-loaded foam cells [24], an early sign of atherosclerosis, we next examined whether expression of USF1 has an effect on cholesterol accumulation in macrophages. For this aim, we measured the content of cholesterol in peritoneal macrophages from $U_{s f 1^{+/+}}$and $U_{s f 1^{-/-}}$mice after incubation of the cells with acetylated LDL in the absence or presence of lipopolysaccharide (LPS), a potent proinflammatory activator of macrophages. We found that while in the absence of LPS there was no difference, in 


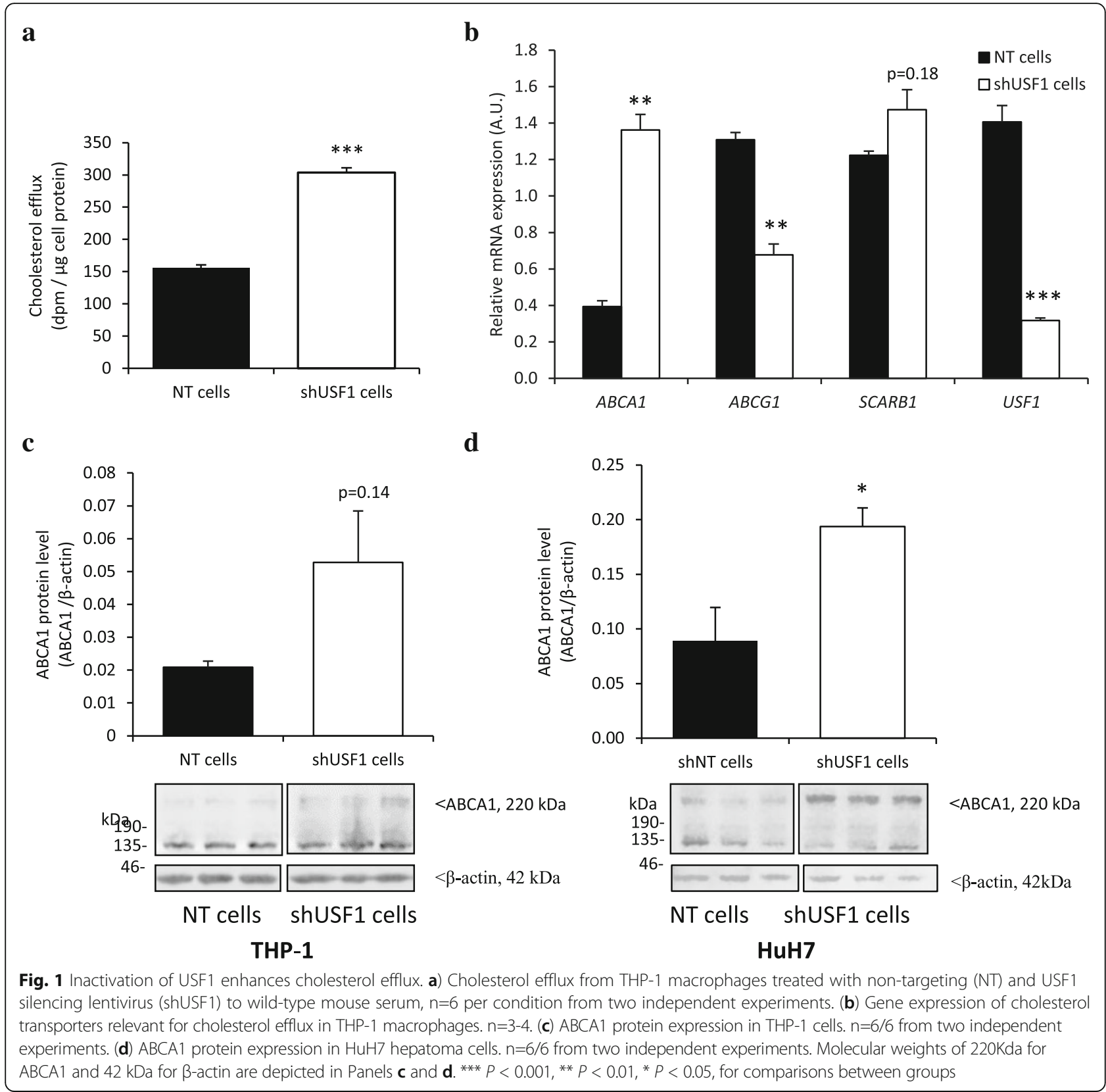

the presence of LPS the cholesterol accumulation induced by acLDL was $48 \%$ lower in Usf1 deficient macrophages as compared to wild type cells (Fig. 3a). Usf1 deficiency thus confers resistance to LPS-induced proinflammatory response in macrophages. The reduced proinflammatory response in Usf1 deficient macrophages was also reflected by lower mRNA expression of NF- $\mathrm{kB}$, including both $N f k b 1$ and $N f k b 2$ (Fig. $3 \mathrm{~b}$ ). Furthermore, secretion of pro-inflammatory cytokines MCP-1 (Fig. 3c) and IL-1 $\beta$ (Fig. 3d) was significantly reduced in USF1-silenced THP-1 macrophages when compared to control cells, demonstrating the presence of a cell-autonomous component of the antiinflammatory effect of USF1 deficiency.

Modified LDL is taken up by several types of scavenger receptors, of which SR-A1 (gene name MSR1) and CD36 are responsible for $>75 \%$ of its internalization [25]. SR-A1 (MSR1) mRNA expression was downregulated by 4.2-fold in USF1 silenced THP-1 macrophages (Fig. 3e), likely explaining the relative resistance conferred by USF1 deficiency to cholesterol accumulation in macrophages observed upon the inflammation-mimicking conditions (LPS exposure). In contrast, the mRNA expression of CD36 was upregulated by 1.7 -fold (Fig. 3e). 


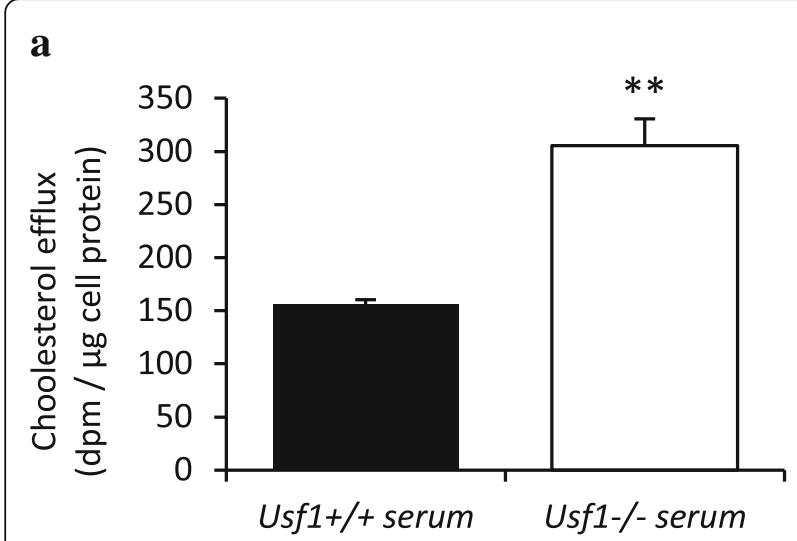

b

c

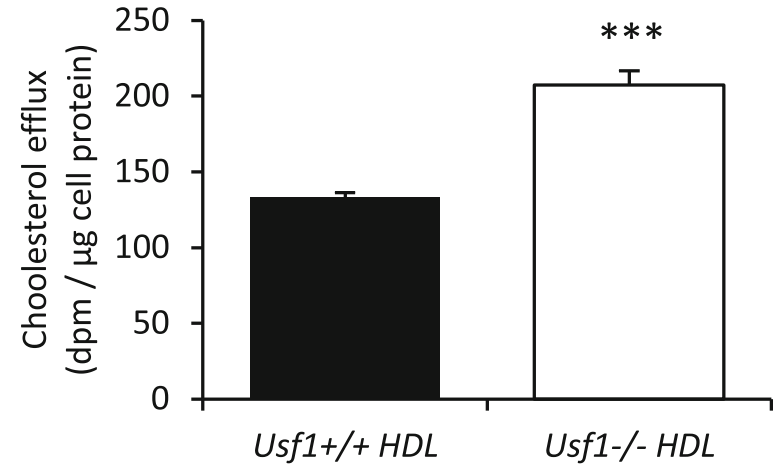

d
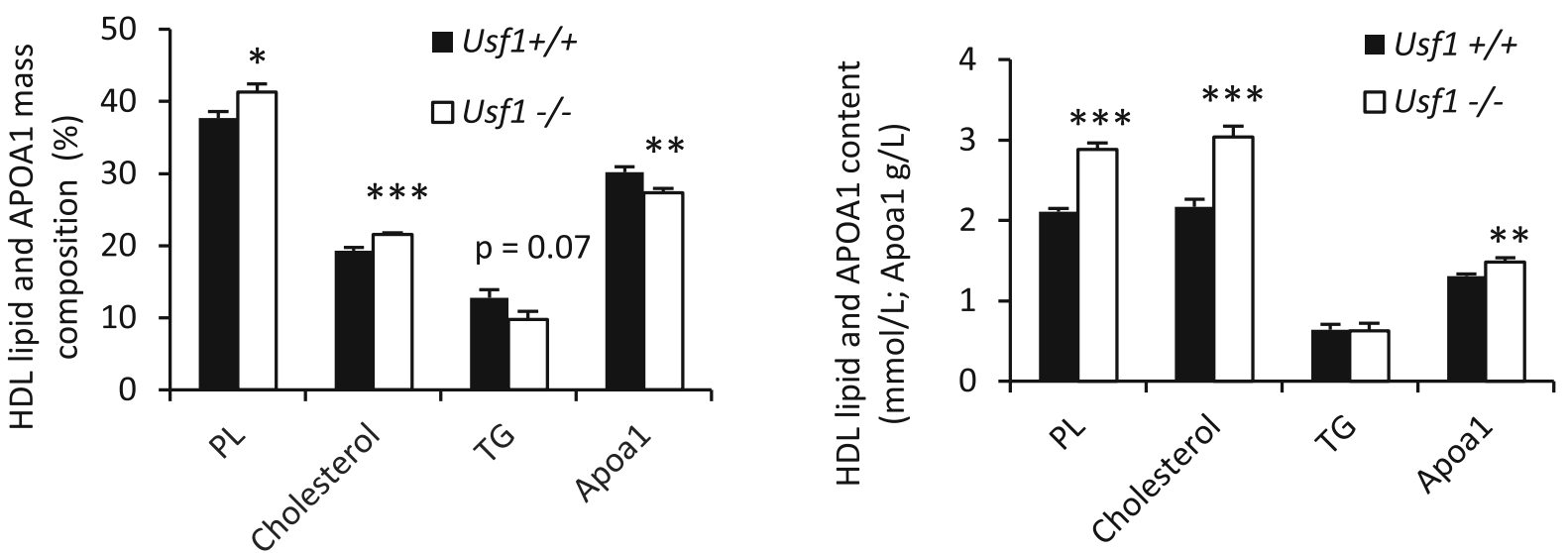

Fig. 2 USF1 deficiency improves acceptor capacity of serum and HDL particles, enriched with phospholipids (PL). (a) Cholesterol efflux from THP1 macrophages to serum derived from Usf1+/+ and Usf1-/- mice. $n=5$ for each column. Serum samples from five individual Usf1+/+ and Usf1-/mice were analyzed in two independent experiments. (b) Cholesterol efflux from THP-1 macrophages to HDL particles derived from Usf1+/+ ( $n=7$ mice, pooled HDL) and Usf1-/- mice ( $n=8$ mice, pooled HDL), $n=6$ parallel wells for THP-1 cells in two independent experiments. (c) Mass composition (\%) of HDL particles isolated from Usf1+/+ and Usf1-/- mice. n=11/9. (d) HDL particle content (mmol/L for lipid and g/L for APOA1), $\mathrm{n}=11 / 9$. ${ }^{* *} P<0.001,{ }^{* *} P<0.01,{ }^{*} P<0.05$, for comparisons between groups

Taken together, by both reducing cholesterol accumulation and enhancing cholesterol efflux, USF1 deficiency prevents cholesterol accumulation in macrophages, thus attenuating foam cell formation.

As macrophage cholesterol efflux is determined not only by the quantity and quality of cholesterol acceptors and transmembrane transporters, but also by the function of intracellular lipid-regulatory enzymes, we next investigated the effect of USF1 on intracellular enzymes affecting cholesterol efflux. Lysosomal acid lipase (LAL; gene name Lipa) is an enzyme responsible for hydrolysis of cholesterol esters. LIPA has been reported to contribute to cholesterol efflux [26], and overexpression of Lipa has been shown to prevent atherogenesis [27, 28]. ACAT1 re-esterifies free cholesterol generated by LIPA to produce cytoplasmic cholesterol ester droplets, and its deficiency results in decreased cholesterol efflux from macrophages [29]. Neutral cholesterol ester hydrolase 1 (Nceh1), located on the cholesterol ester droplets, mediates their hydrolysis in both murine and human macrophages [30], and ablation of Nceh1 accelerates atherosclerosis [31]. To study these intracellular pathways regulating cholesterol efflux, we conducted genome-wide expression array analysis of peritoneal macrophages isolated from $U_{s f 1^{+/+}}$and $U_{s f 1^{-/-}}$ mice. This analysis demonstrated that in the USF1 deficient macrophages the expression of Lipa was upregulated by $63 \%$, Acat 1 by $23 \%$, and Nceh 1 by $41 \%$ (Fig. 4 a). In addition, in THP-1 macrophages similar increases in expression upon USF1 silencing were observed for both NCEH1 and LIPA, but not for ACAT1 (Fig. 4b). In functional analysis, however, measurement of macrophage cholesterol esterification by a radiometric assay showed no significant difference between USF1 silenced (14,805 \pm $1266 \mathrm{dpm} / \mathrm{mg}$ protein) and control THP-1 macrophage cells $(12,500 \pm 2327 \mathrm{dpm} / \mathrm{mg}$ protein). We further analyzed the impact of USF1 silencing on the distribution of 


\section{$\mathbf{a}$}

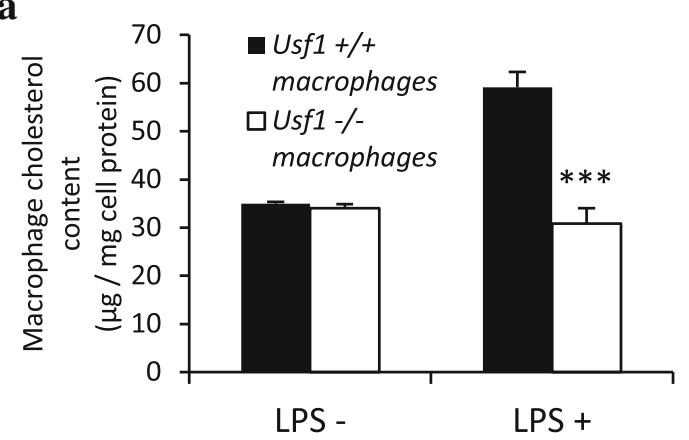

c

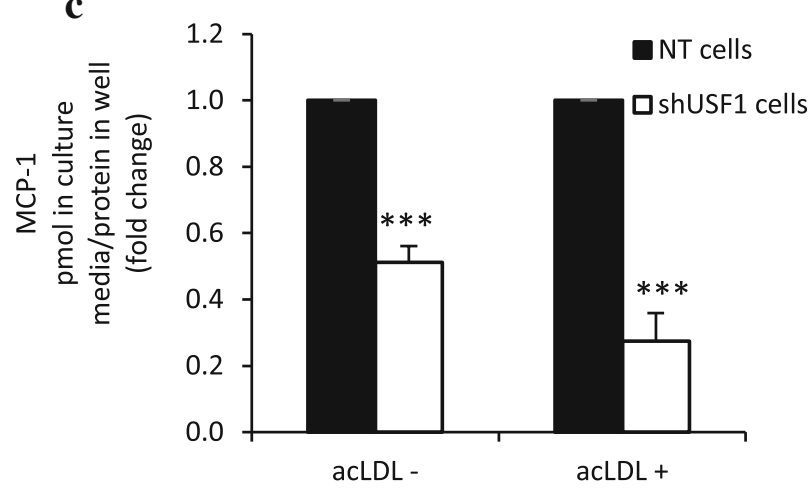

e

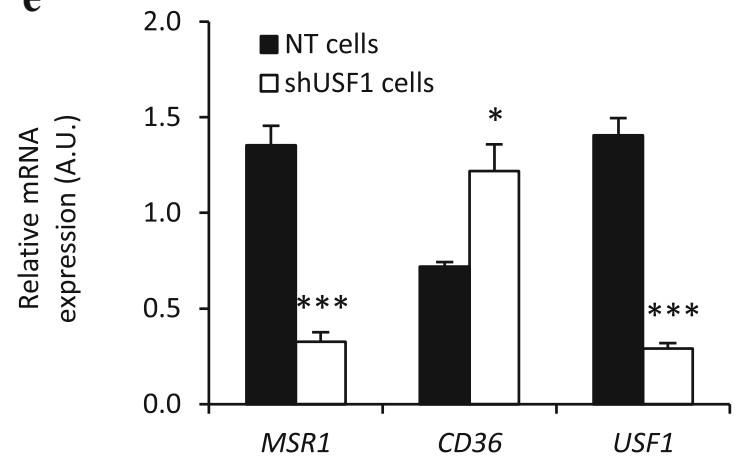

b

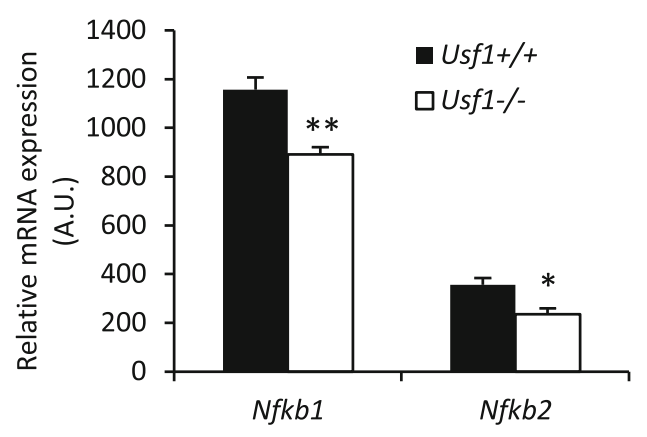

d

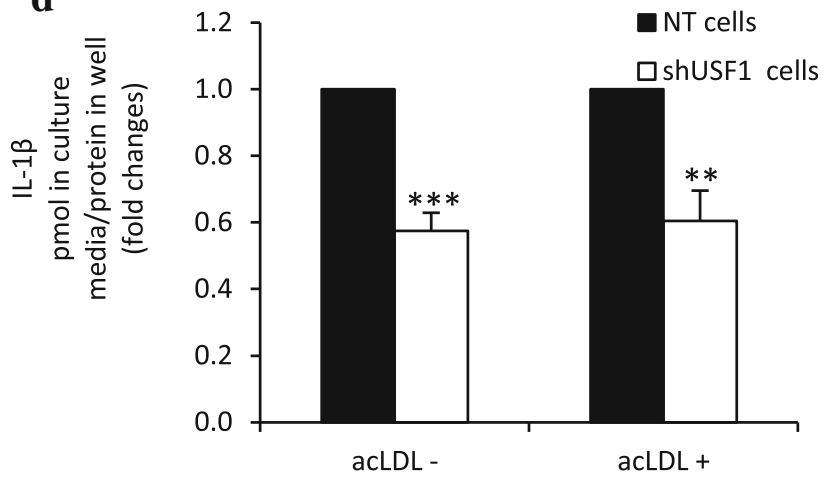

Fig. 3 USF1 deficiency attenuates LPS-induced proinflammatory responses of macrophages and protects against inflammation-induced cholesterol accumulation. (a) Cholesterol content of mouse peritoneal macrophages incubated without or with LPS. $n=4 / 5 / 9 / 8$ parallel wells in two independent experiments. (b) Expression of Nfkb1 and Nfkb2 (NF-KB) in peritoneal macrophages in the absence of LPS. $n=4 / 4$. (c) Secretion of MCP-1 from THP-1 macrophages +/- acLDL, $\mathrm{n}=6$ from 2 independent experiments. (d) Secretion of IL-1 $\beta$ from THP-1 macrophages $+/-$ acLDL, $\mathrm{n}=6$ from 2 independent experiments. (e) Gene expression of cholesterol transporters relevant for cholesterol uptake in THP-1 macrophages in the absence of LPS. $\mathrm{n}=4$ in each column. ${ }^{* *} P<0.001,{ }^{* *} P<0.01,{ }^{*} P<0.05$, for comparisons between groups

$\left[{ }^{14}\right]$-cholesterol between unesterified and esterified intracellular pools in the THP-1 macrophages in the absence and presence of acLDL loading. These experiments revealed no significant difference in the $\left[{ }^{14} \mathrm{C}\right] \mathrm{CE} /$ total $\mathrm{C}$ ratio (no acLDL loading: shNT, $0.0549 \pm 0.0135 \mathrm{cpm} / \mathrm{cpm}$; shUSF1, $0.0676 \pm 0.0316 \mathrm{cpm} / \mathrm{cpm}$, and acLDL loading: shNT, $0.3641 \pm 0.0464 \mathrm{cpm} / \mathrm{cpm}$; shUSF1, $0.4374 \pm 0.0108$ $\mathrm{cpm} / \mathrm{cpm}$ ) or in the $\left[{ }^{14} \mathrm{C}\right] \mathrm{CE} /$ total protein ratio (no acLDL loading: shNT, $3.508 \pm 0.424 \mathrm{cpm} / \mu \mathrm{g}$ protein; shUSF1, $4.047 \pm 0.225 \mathrm{cpm} / \mu \mathrm{g}$ protein, and acLDL loading; shNT,
$22.801 \pm 7.906 \mathrm{cpm} / \mu \mathrm{g}$ protein; shUSF1, $27.215 \pm 3.508$ $\mathrm{cpm} / \mu \mathrm{g}$ protein). Although we did not observe differences in the ACAT-mediated cholesterol esterification or the distribution of $\left[{ }^{14} \mathrm{C}[-\right.$-cholesterol, the enhanced cholesterol efflux and the elevated expression of $A B C A 1$ mRNA and protein, as well as the altered mRNAs expression of LIPA and NCEH1 imply that the effects of Usf1 deficiency extend to inducing modulation of intracellular cholesterol pathways which also contribute to the enhancement of macrophage cholesterol efflux. 

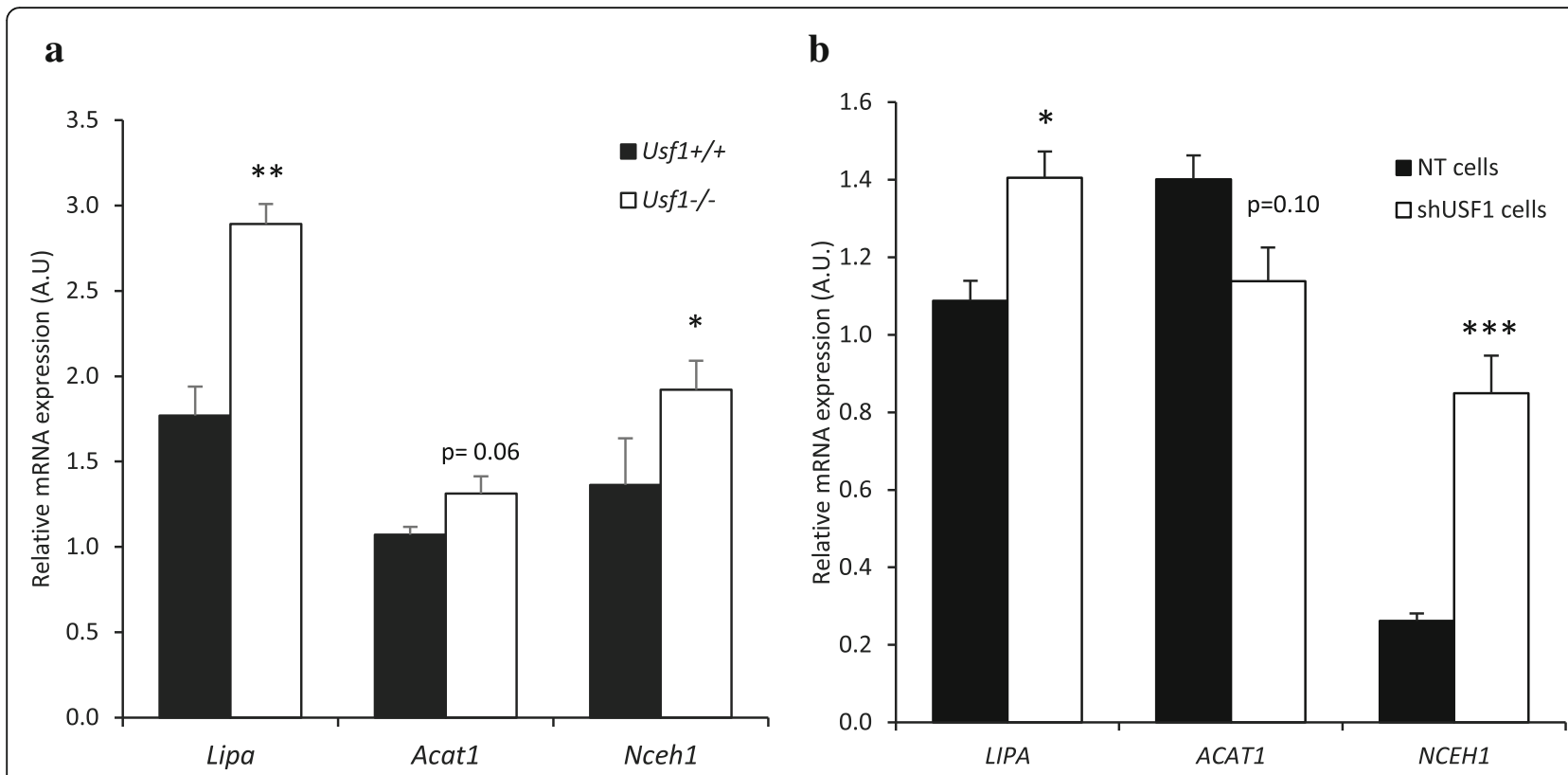

Fig. 4 Intracellular cholesterol pathways are upregulated upon USF1 deficiency. (a) Lipa, Acat1 and Nceh1 mRNA expression in mouse peritoneal macrophages. $n=5 / 5$ (individual animals). (b) LIPA, ACAT1 and NCEH1 mRNA expression in THP-1 macrophages. $n=4 / 3$; for NCEH $n=3$ per group. ** $P<0.01, * P<0.05$, for comparisons between groups

\section{Discussion}

In this study we have identified USF1 as a novel factor affecting HDL functionality, thus having an impact on HDL metabolism beyond its effects on the levels of HDL-C. The majority of epidemiological studies of HDL functionality have recently focused on macrophage cholesterol efflux $[7,8]$. These studies have shown that cholesterol efflux is inversely proportional to CVD risk, and demonstrated cholesterol efflux to be a better CVD risk predictor than HDL-C levels. Thus, cholesterol efflux facilitated by HDL merits further study, and factors boosting cholesterol efflux could potentially provide antiatherogenic effects. Based on our study, USF1 appears to be such factor, regulating the cholesterol acceptor properties of HDL particles, such their phospholipid (PL) content. Moreover, we show evidence that USF1 modulates the expression of cholesterol transporters (SR-A1, ABCA1), and gene expression of critical metabolic pathways of intracellular cholesterol ester hydrolyzing and esterifying enzymes crucial for the intracellular cholesterol turnover in macrophages. These observations are summarized in Fig. 5 and discussed below.

First, USF1 silencing activated cholesterol removal from macrophages. This enhancement in cholesterol release capacity was most likely due to enhanced ABCA1-mediated cholesterol efflux. The results agree well with previous studies in which USF1 was identified as a repressor of $A B C A 1[19,32]$. The expression of $S C A R B 1$, a passive transporter, was unchanged, while the mRNA level of $A B C G 1$ was decreased. It is possible that $A B C G 1$ expression could be reduced in response to the change in cholesterol status of the cells, as ABCA1 expression has been increased by a mechanism that may not affect ABCG1. This finding requires further study. The observations suggest that upon USF1 deficiency, ABCA1 mediated cholesterol efflux is the major pathway responsible for net macrophage cholesterol efflux. As ABCA1 protein was increased in USF1 silenced hepatocytes, USF1 deficiency could also contribute to elevated plasma HDL-C levels by enhancing secretion of nascent HDL particles from the liver.

Second, USF1 deficiency improved macrophage cholesterol efflux also through conferring enhanced cholesterol acceptor capacity to serum and HDL particles. The $U_{s} \mathrm{f}^{-{ }^{--}}$-derived HDL particles exhibited higher phospholipid content than those of $U_{s f 1^{+/+}}$mice, and since Fournier et al. have previously shown that HDL phospholipid content is the major factor determining HDL-dependent cholesterol efflux [22], our results point to elevated phospholipid content being one important factor responsible for the enhanced acceptor capacity of $U s f 1^{-/-}$-derived HDL particles (Fig. 5).

Third, USF1 deficiency increased the gene expression of intracellular enzymes affecting macrophage cholesterol metabolism. Of these enzymes, LIPA and NCEH1 are responsible for cholesterol ester hydrolysis, releasing unesterified cholesterol and fatty acids, and ACAT1 for re-esterification of cholesterol. High levels of NCEH1 and LIPA have been shown to protect against atherosclerosis $[28,31]$, and they are associated with increased cholesterol efflux $[27,30]$. The upregulation of these 


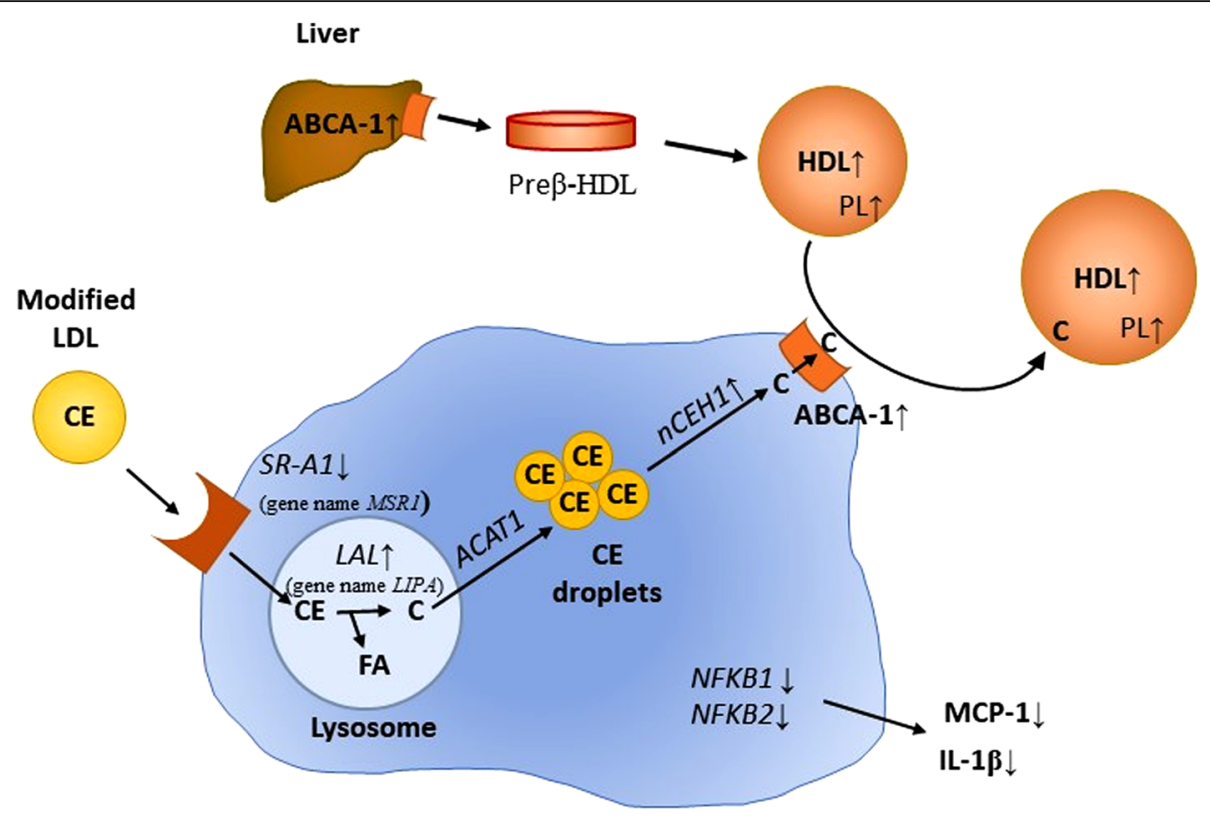

\section{USF1-deficient macrophage foam cell}

Fig. 5 Schematic presentation of the proposed mechanism for the effects of USF1 deficiency on cholesterol flux through a macrophage foam cell. Uptake of cholesteryl esters (CE) present in the core of modified LDL particles promotes the generation of macrophage foam cells. Modified LDL is taken up by scavenger receptors, such as SR-A1. Lack of USF1 resulted in reduced mRNA levels of SR-A1 and attenuated LPS-induced macrophage cholesterol deposition. Intracellular cholesterol flux-regulating enzymes, lysosomal acid lipase (LAL, gene name LIPA), acetyl-CoA cholesterol acyltransferase 1 (ACAT1) and neutral cholesterol ester hydrolase 1 (nCEH1) are key factors modulating macrophage cholesterol metabolism. Deficiency of Usf1 caused an upregulation in expression of NCEH1 and LIPA in both mouse peritoneal macrophages and human THP-1 cells, thereby enhancing intracellular cholesterol flux from lysosomes via CE droplets to plasma membrane. The protein expression of $\mathrm{ABCA1}$, an important cholesterol transporter on macrophage plasma membrane, was also increased due to lack of USF1, further accelerating the removal of cholesterol to cholesterol acceptors (HDL), whose plasma levels were elevated in Usf1 deficient mice (16). The HDL particles derived from Usf1-/- mice had a higher proportion of phospholipids (PL) in HDL further explaining the elevated cholesterol acceptor capacity of Usf1-/derived HDL particles. ABCA1 protein levels were upregulated in USF1 deficient hepatocytes, which may partially explain the elevated HDL levels in USF1 deficient mice. Expression of NF-KB, a key regulator of inflammation was decreased in peritoneal macrophages from USF1 deficient mice and, furthermore, secretion of cytokines (MCP-1 and IL-1 $\beta$ ) was found to be decreased in USF1 silenced THP-1 macrophages. Arrows denote the effects of USF1 deficiency at relevant sites

mRNAs potentially indicates a higher rate of cholesterol trafficking in the cell, resulting in enhanced cellular cholesterol transfer to acceptors (Fig. 5). However, in radiolabeling experiments, we did not observe a significant difference in cholesterol esterification or $\left[{ }^{14} \mathrm{C}\right]$-cholesterol distribution between unesterified and esterified pools between USF1 deficient and control cells. This is consistent with a model in which the intracellular turnover of cholesterol in USF1 deficient cells is enhanced, making it more readily available for ABCA1-mediated efflux to HDL acceptors (Fig. 5).

Usf1 deficiency protected against LPS-induced increase in cholesterol deposition into macrophages. LPS has been implicated in human cardiovascular disease [33], and is thought to contribute to the development of arterial plaques through activation of pro-inflammatory pathways [34]. The chronic low-grade inflammation associated with dyslipidemia predisposes to atherosclerosis via the formation of foam cells. Thus, the atheroprotective effect of Usf1 deficiency in $\mathrm{Ldlr}^{-1-}$ background [16] could be partly mediated by the attenuated formation of foam cells despite the severe hyperlipidemia observed in $\mathrm{Ldlr}^{-/-}$background. The reduced cholesterol accumulation in the present study is likely explained by the reduction in scavenger receptor SR-A1 (gene MSR1) whose mRNA expression was decreased following USF1 depletion. On the other hand, the mRNA expression of CD36, another scavenger receptor, was elevated. While this finding may first seem contradictory, it appears more plausible considering that CD36 is a marker of anti-inflammatory M2 macrophages [35]. In fact, as the expression of NF-kB was down-regulated in USF1 deficient macrophages as well as the secretion of pro-inflammatory cytokines MCP- 1 and IL-1 $\beta$, increased CD36 expression is well in line with the general anti-inflammatory status conferred by Usf1 deficiency 
[16]. The anti-inflammatory environment most likely repels cholesterol accumulation into macrophages.

This study, showing that Usf1 deficiency enhances cholesterol efflux, lowers macrophage inflammatory status, and reduces cholesterol accumulation, supports and expands our previous findings, in which we showed that Usf1 deficiency results in higher HDL-C, lower triglycerides, and protection against diet-induced obesity, insulin resistance, systemic inflammation, and atherosclerosis [16]. Mice lacking Usf1 on $\mathrm{Ldlr}^{-1-}$ background displayed a 4-fold reduction in atherosclerosis, and human individuals harboring an allele associated with $18 \%$ reduction in USF1 mRNA displayed a $45 \%$ reduction in plaque area in coronary arteries as well as $47 \%$ reduction in plaque calcification. While the causal relationship between elevated cholesterol efflux and CVD events remains to be proven in future studies, our study is well in line with epidemiological reports showing enhanced cholesterol efflux capacity to be associated with reduction in CVD events [7], and provides further support for the importance of functional improvement of HDL particles regarding atheroprotection. The present study includes some important limitations: It is possible that USF1 regulates macrophage polarization between $\mathrm{M} 1$ and M2, which could affect the results. Further, although we report an elevated total phospholipid content in HDL derived from $U s f 1$ deficient mice, the mechanism behind this observation remains unknown. Finally, thorough HDL phospholipidomics and proteomics analyses would be relevant in order to address in more detail the impact of Usf1 deficiency on HDL function in cholesterol efflux. These issues are important goals for the future studies.

\section{Conclusions}

We have identified USF1 as a novel factor affecting macrophage inflammatory status and cholesterol homeostasis, whose deficiency not only raises HDL-C levels, but, more importantly, improves HDL functionality and reduces inflammation.

\footnotetext{
Abbreviations

ABCA1: ATP-binding Cassette Transporter A1; ACAT1: Acyl-CoA: Cholesterol Acyltransferase 1; apoA-l: apolipoprotein A-l; C: Cholesterol; CE: Cholesterol ester; CVD: Cardiovascular disease; HDL-C: High-density lipoprotein cholesterol; IL-13: Interleukin 13; LAL: Lysosomal acid lipase; LDL: Low-density lipoprotein; LPS: Lipopolysaccharide; MCP-1: Monocyte chemoattractant protein 1; NCEH1: Neutral cholesterol ester hydrolase 1; NF-KB: Nuclear factor- KB; PL: Phospholipids; SR-A1: Scavenger receptor A1; USF1: Upstream stimulatory factor 1
}

\section{Acknowledgements}

Sari Nuutinen and Liisa Arala are acknowledged for expert technical assistance, and Academician of Science Leena Peltonen-Palotie for the initial support to this study. The authors declare no conflict of interest relevant to this study.

\section{Funding}

This study was supported by the Finnish Foundation for Cardiovascular Research (MJ, VMO, PPL, JS), Jenny and Antti Wihuri Foundation (MJ, JS), Novo-Nordisk Foundation (MRT, VMO), Paavo Nurmi Foundation (MJ, PPL, JS,
VMO), Academy of Finland (Grant \#257545 to MJ and \#265940 to KÖ), Finska Läkaresällskapet (PPL), Aarne Koskelo Foundation (PPL), Emil Aaltonen Foundation (PPL), Foundation for Diabetes Research (PPL, JS), Magnus Ehrnrooth Foundation (PPL, VMO), Jane and Aatos Erkko Foundation (MJ), Sigrid Juselius Foundation (PPL, VMO) and The Finnish Medical Foundation (PPL). Wihuri Research Institute (MR, MLR, KÖ, PTK) is maintained by the Jenny and Antti Wihuri Foundation.

Availability of the data and materials

All data generated or analyzed during this study are included in this manuscript.

\section{Authors' contributions}

PPL, MSJ, JS and VMO designed the study; EK, PPL, JS and MSJ performed the animal study and tissue preparations; MR, EK, KM, JP, JM and ML-R performed macrophage and hepatocyte experiments; PPL, MSJ, VMO, PTK, and KÖ wrote the manuscript; MSJ, MR, and VMO revised the manuscript. All authors read and approved the final version of the manuscript.

\section{Ethics approval}

All animal procedures were reviewed and approved by the local animal care committee and local government authorities.

\section{Consent for publication}

Not applicable

\section{Competing interests}

The authors declare that they have no competing interests, financial or otherwise essential.

\section{Publisher's Note}

Springer Nature remains neutral with regard to jurisdictional claims in published maps and institutional affiliations.

\section{Author details}

${ }^{1}$ Wihuri Research Institute, Fl-00290 Helsinki, Finland. ${ }^{2}$ Research Program Unit, University of Helsinki, Fl-00014 Helsinki, Finland. ${ }^{3}$ Genomics and Biomarkers Unit, National Institute for Health and Welfare, FI-00251 Helsinki, Finland. ${ }^{4}$ Minerva Foundation Institute for Medical Research, Tukholmankatu 8, 00290 Helsinki, Finland. ${ }^{5}$ Diabetes and Obesity Research Program, University of Helsinki, Fl-00014 Helsinki, Finland. ${ }^{6}$ Department of Anatomy, Faculty of Medicine, University of Helsinki, Fl-00014 Helsinki, Finland. 'Department of Medical and Clinical Genetics, University of Helsinki, Fl-00014 Helsinki, Finland. ${ }^{8}$ Institute for Molecular Medicine Finland, FIMM, FI-00251 Helsinki, Finland.

Received: 13 August 2018 Accepted: 26 November 2018 Published online: 13 December 2018

\section{References}

1. Robinson JG, Stone NJ. The 2013 ACC/AHA quideline on the treatment of blood cholesterol to reduce atherosclerotic cardiovascular disease risk: a new paradigm supported by more evidence. Eur Heart J. 2015;36:2110-8.

2. Barter PJ, Caulfield M, Eriksson M, Grundy SM, Kastelein JJ, Komajda M, Lopez-Sendon J, Mosca L, Tardif JC, Waters DD, Shear CL, Revkin JH, Buhr KA, Fisher MR, Tall AR, Brewer B, Investigators ILLUMINATE. Effects of torcetrapib in patients at high risk for coronary events. N Engl J Med. 2007; 357:2109-22.

3. HPS2-THRIVE Collaborative Group, Landray MJ, Haynes R, Hopewell JC, Parish S, Aung T, Tomson J, Wallendszus K, Craig M, Jiang L, Collins R, Armitage J. Effects of extended-release niacin with laropiprant in high-risk patients. N Engl J Med. 2014;371:203-12.

4. Investigators AIM-HIGH, Boden WE, Probstfield $J$, Anderson T, Chaitman BR, Desvignes-Nickens P, Koprowicz K, McBride R, Teo K, Weintraub W. Niacin in patients with low HDL cholesterol levels receiving intensive statin therapy. N Engl J Med. 2011;365:2255-67.

5. Voight BF, Peloso GM, Orho-Melander M, Frikke-Schmidt R, Barbalic M, Jensen MK, Hindy G, Holm H, Ding EL, Johnson T, Schunkert H, Samani NJ, Clarke R, Hopewell JC, Thompson JF, Li M, Thorleifsson G, Newton-Cheh C, Musunuru K, Pirruccello JP, Saleheen D, Chen L, Stewart A, Schillert A, Thorsteinsdottir U, Thorgeirsson G, Anand S, Engert JC, Morgan T, Spertus J, Stoll M, Berger K, Martinelli N, Girelli D, McKeown PP, Patterson CC, Epstein 
SE, Devaney J, Burnett MS, Mooser V, Ripatti S, Surakka I, Nieminen MS, Sinisalo J, Lokki ML, Perola M, Havulinna A, de Faire U, Gigante B, Ingelsson $\mathrm{E}$, Zeller T, Wild P, de Bakker PI, Klungel OH, Maitland-van der Zee AH, Peters BJ, de Boer A, Grobbee DE, Kamphuisen PW, Deneer VH, Elbers CC, Onland-Moret NC, Hofker MH, Wijmenga C, Verschuren WM, Boer JM, van der Schouw YT, Rasheed A, Frossard P, Demissie S, Willer C, Do R, Ordovas JM, Abecasis GR, Boehnke M, Mohlke KL, Daly MJ, Guiducci C, Burtt NP, Surti A, Gonzalez E, Purcell S, Gabriel S, Marrugat J, Peden J, Erdmann J, Diemert P, Willenborg C, Konig IR, Fischer M, Hengstenberg C, Ziegler A, Buysschaert I, Lambrechts D, Van de Werf F, Fox KA, El Mokhtari NE, Rubin D, Schrezenmeir J, Schreiber S, Schafer A, Danesh J, Blankenberg S, Roberts R, McPherson R, Watkins H, Hall AS, Overvad K, Rimm E, Boerwinkle E, Tybjaerg-Hansen A, Cupples LA, Reilly MP, Melander O, Mannucci PM, Ardissino D, Siscovick D, Elosua R, Stefansson K, O'Donnell CJ, Salomaa V, Rader DJ, Peltonen L, Schwartz SM, Altshuler D, Kathiresan S. Plasma HDL cholesterol and risk of myocardial infarction: a mendelian randomisation study. Lancet. 2012;380:572-80.

6. Toth PP, Barter PJ, Rosenson RS, Boden WE, Chapman MJ, Cuchel M, D'Agostino S, RB MHD, Davidson WS, Heinecke JW, Karas RH, Kontush A, Krauss RM, Miller M, Rader DJ. High-density lipoproteins: a consensus statement from the National Lipid Association. J Clin Lipidol. 2013;7:484-525.

7. Khera AV, Cuchel M, de la Llera-Moya M, Rodrigues A, Burke MF, Jafri K, French BC, Phillips JA, Mucksavage ML, Wilensky RL, Mohler ER, Rothblat GH, Rader DJ. Cholesterol efflux capacity, high-density lipoprotein function, and atherosclerosis. N Engl J Med. 2011;364:127-35.

8. Rohatgi A, Khera A, Berry JD, Givens EG, Ayers CR, Wedin KE, Neeland IJ, Yuhanna IS, Rader DR, de Lemos JA, Shaul PW. HDL cholesterol efflux capacity and incident cardiovascular events. N Engl J Med. 2014;371:2383-93.

9. Eckardstein A. Tachometer for reverse cholesterol transport? J Am Heart Assoc. 2012;1:e003723.

10. Pajukanta P, Lilja HE, Sinsheimer JS, Cantor RM, Lusis AJ, Gentile M, Duan XJ, Soro-Paavonen A, Naukkarinen J, Saarela J, Laakso M, Ehnholm C, Taskinen MR, Peltonen L. Familial combined hyperlipidemia is associated with upstream transcription factor 1 (USF1). Nat Genet. 2004;36:371-6.

11. Laurila PP, Naukkarinen J, Kristiansson K, Ripatti S, Kauttu T, Silander K, Salomaa V, Perola M, Karhunen PJ, Barter PJ, Ehnholm C, Peltonen L. Genetic association and interaction analysis of USF1 and APOA5 on lipid levels and atherosclerosis. Arterioscler Thromb Vasc Biol. 2010;30:346-52.

12. Putt W, Palmen J, Nicaud V, Tregouet DA, Tahri-Daizadeh N, Flavell DM, Humphries SE, Talmud PJ. Variation in USF1 shows haplotype effects, gene : gene and gene : environment associations with glucose and lipid parameters in the European atherosclerosis research study II. Hum Mol Genet. 2004;13:1587-97.

13. Huertas-Vazquez A, Aguilar-Salinas C, Lusis AJ, Cantor RM, CanizalesQuinteros S, Lee JC, Mariana-Nunez L, Riba-Ramirez RM, Jokiaho A, Tusie-Luna T, Pajukanta P. Familial combined hyperlipidemia in Mexicans: association with upstream transcription factor 1 and linkage on chromosome 16q24.1. Arterioscler Thromb Vasc Biol. 2005;25:1985-91.

14. Kristiansson K, Ilveskoski E, Lehtimaki T, Peltonen L, Perola M, Karhunen PJ. Association analysis of allelic variants of USF1 in coronary atherosclerosis. Arterioscler Thromb Vasc Biol. 2008;28:983-9.

15. Komulainen K, Alanne M, Auro K, Kilpikari R, Pajukanta P, Saarela J, Ellonen P, Salminen K, Kulathinal S, Kuulasmaa K, Silander K, Salomaa V, Perola M, Peltonen L. Risk alleles of USF1 gene predict cardiovascular disease of women in two prospective studies. PLoS Genet. 2006;2:e69.

16. Laurila PP, Soronen J, Kooijman S, Forsstrom S, Boon MR, Surakka I, Kaiharju E, Coomans CP, Van Den Berg SA, Autio A, Sarin AP, Kettunen J, Tikkanen E, Manninen T, Metso J, Silvennoinen R, Merikanto K, Ruuth M, Perttila J, Makela A, Isomi A, Tuomainen AM, Tikka A, Ramadan UA, Seppala I, Lehtimaki T, Eriksson J, Havulinna A, Jula A, Karhunen PJ, Salomaa V, Perola M, Ehnholm C, Lee-Rueckert M, Van Eck M, Roivainen A, Taskinen MR, Peltonen L, Mervaala E, Jalanko A, Hohtola E, Olkkonen VM, Ripatti S, Kovanen PT, Rensen PC, Suomalainen A, Jauhiainen M. USF1 deficiency activates brown adipose tissue and improves cardiometabolic health. Sci Transl Med. 2016:8:323ra13.

17. van Haperen $R$, van Tol $A$, Vermeulen $P$, Jauhiainen $M$, van Gent $T$, van den Berg $P$, Ehnholm S, Grosveld F, vand der Kamp A, de Crom R. Human plasma phospholipid transfer protein increases the antiatherogenic potential of high density lipoproteins in transgenic mice. Arterioscler Thromb Vasc Biol. 2000;20:1082-8.

18. Wu Z, Irizarry R, Gentleman R, Martinez-Murillo F, Spencer F. A model-based background adjustment for oligonucleotide expression arrays. J Am Stat Assoc. 2004;99:909-17.
19. Yang XP, Freeman LA, Knapper $C L$, Amar MJ, Remaley A, Brewer HB Jr, Santamarina-Fojo S. The E-box motif in the proximal ABCA1 promoter mediates transcriptional repression of the ABCA1 gene. J Lipid Res. 2002:43:297-306.

20. Yetukuri L, Soderlund S, Koivuniemi A, Seppanen-Laakso T, Niemela PS, Hyvonen M, Taskinen MR, Vattulainen I, Jauhiainen M, Oresic M. Composition and lipid spatial distribution of HDL particles in subjects with low and high HDL-cholesterol. J Lipid Res. 2010;51:2341-51.

21. Laurila PP, Surakka I, Sarin AP, Yetukuri L, Hyotylainen T, Soderlund S, Naukkarinen J, Tang J, Kettunen J, Mirel DB, Soronen J, Lehtimaki T, Ruokonen A, Ehnholm C, Eriksson JG, Salomaa V, Jula A, Raitakari OT, Jarvelin MR, Palotie A, Peltonen L, Oresic M, Jauhiainen M, Taskinen MR, Ripatti S. Genomic, transcriptomic, and lipidomic profiling highlights the role of inflammation in individuals with low high-density lipoprotein cholesterol. Arterioscler Thromb Vasc Biol. 2013:33:847-57.

22. Fournier, N., M. de la Llera Moya, B. F. Burkey, J. B. Swaney, J. Paterniti Jr, N. Moatti, V. Atger, and G. H. Rothblat. 1996. Role of HDL phospholipid in efflux of cell cholesterol to whole serum: studies with human apoA-I transgenic rats. J Lipid Res 37: 1704-1711.

23. Gelissen IC, Harris M, Rye KA, Quinn C, Brown AJ, Kockx M, Cartland S, Packianathan $M$, Kritharides $L$, Jessup W. ABCA1 and ABCG1 synergize to mediate cholesterol export to apoA-I. Arterioscler Thromb Vasc Biol. 2006;26:534-40.

24. Yu XH, Fu YC, Zhang DW, Yin K, Tang CK. Foam cells in atherosclerosis. Clin Chim Acta. 2013;424:245-52.

25. Kunjathoor W, Febbraio M, Podrez EA, Moore KJ, Andersson L, Koehn S, Rhee JS, Silverstein R, Hoff HF, Freeman MW. Scavenger receptors class A-1/II and CD36 are the principal receptors responsible for the uptake of modified low density lipoprotein leading to lipid loading in macrophages. J Biol Chem. 2002:277:49982-8.

26. Ouimet M, Franklin V, Mak E, Liao X, Tabas I, Marcel YL. Autophagy regulates cholesterol efflux from macrophage foam cells via lysosomal acid lipase. Cell Metab. 2011;13:655-67.

27. Du H, Grabowski GA. Lysosomal acid lipase and atherosclerosis. Curr Opin Lipidol. 2004;15:539-44.

28. Du H, Schiavi S, Wan N, Levine M, Witte DP, Grabowski GA. Reduction of atherosclerotic plaques by lysosomal acid lipase supplementation. Arterioscler Thromb Vasc Biol. 2004:24:147-54.

29. Dove DE, Su YR, Zhang W, Jerome WG, Swift LL, Linton MF, Fazio S. ACAT1 deficiency disrupts cholesterol efflux and alters cellular morphology in macrophages. Arterioscler Thromb Vasc Biol. 2005;25:128-34.

30. Igarashi M, Osuga J, Uozaki H, Sekiya M, Nagashima S, Takahashi M, Takase S, Takanashi M, Li Y, Ohta K, Kumagai M, Nishi M, Hosokawa M, Fledelius C, Jacobsen P, Yagyu H, Fukayama M, Nagai R, Kadowaki T, Ohashi K, Ishibashi S. The critical role of neutral cholesterol ester hydrolase 1 in cholesterol removal from human macrophages. Circ Res. 2010;107:1387-95.

31. Sekiya M, Osuga J, Nagashima S, Ohshiro T, Igarashi M, Okazaki H, Takahashi M, Tazoe F, Wada T, Ohta K, Takanashi M, Kumagai M, Nishi M, Takase S, Yahagi N, Yagyu H, Ohashi K, Nagai R, Kadowaki T, Furukawa Y, Ishibashi S. Ablation of neutral cholesterol ester hydrolase 1 accelerates atherosclerosis. Cell Metab. 2009;10:219-28.

32. Pan $\mathrm{X}$, Jiang $\mathrm{XC}$, Hussain MM. Impaired cholesterol metabolism and enhanced atherosclerosis in clock mutant mice. Circulation. 2013;128:1758-69.

33. Kallio KA, Buhlin $K$, Jauhiainen $M$, Keva R, Tuomainen AM, Klinge $B$, Gustafsson A, Pussinen PJ. Lipopolysaccharide associates with proatherogenic lipoproteins in periodontitis patients. Innate Immun. 2008; 14:247-53.

34. Lehr HA, Sagban TA, Ihling C, Zahringer U, Hungerer KD, Blumrich M, Reifenberg K, Bhakdi S. Immunopathogenesis of atherosclerosis: endotoxin accelerates atherosclerosis in rabbits on hypercholesterolemic diet. Circulation. 2001;104:914-20.

35. Huang SC, Everts B, Ivanova Y, O'Sullivan D, Nascimento M, Smith AM, Beatty W, Love-Gregory L, Lam WY, O'Neill CM, Yan C, Du H, Abumrad NA, Urban JF Jr, Artyomov MN, Pearce EL, Pearce EJ. Cell-intrinsic lysosomal lipolysis is essential for alternative activation of macrophages. Nat Immunol. 2014;15:846-55. 